\title{
Reasons for Use of and Experiences with Homeopathic Treatment as an Adjunct to Usual Cancer Care: Results of a Small Qualitative Study
}

\author{
Charlotte Yde ${ }^{1}$ Petter Viksveen ${ }^{2}$ Jean Duckworth ${ }^{3}$ \\ 1 Odense C, Denmark \\ ${ }^{2}$ Centre for Resilience in Healthcare (SHARE), Faculty of Health \\ Sciences, University of Stavanger, Stavanger, Norway \\ ${ }^{3}$ School of Community Health and Midwifery, University of Central \\ Lancashire, Preston, Lancashire, United Kingdom \\ Homeopathy 2019;108:24-32.
}

Address for correspondence Charlotte Yde, BSc, MSc, Danmarksgade 27, 5000 Odense C, Denmark (e-mail: mail@charlotteyde.dk).

\author{
Abstract \\ Keywords \\ - qualitative \\ - complementary and \\ alternative medicine \\ - homeopathy \\ - cancer \\ - thematic analysis
}

Background A significant proportion of patients with cancer consult with homeopaths. No former qualitative study has reported on experiences with homeopathy in this patient group. This study aimed to learn about the reasons for, and experiences with, treatment provided by homeopaths among Danish patients with cancer.

Methods A small qualitative semi-structured interview study was carried out to collect preliminary knowledge to learn about reasons for and experiences with treatment provided by homeopaths as an adjunct to usual care among patients with cancer. Thematic analysis was used for the development of themes.

Results Five patients, diagnosed with cancer, were interviewed. On the basis of qualitative interviews five themes emerged: concerns and hopes, obstacles and support, internal health locus of control, whole person approach, and improved well-being.

Conclusion The cancer patients in this study sought homeopathy to address their hopes and concerns and to help them face obstacles and find support. They were actively taking responsibility for their own health and valued the whole person approach used by their homeopaths. Participants reported improved well-being both at the physical and mental levels. The results provide a basis for further research to learn more from patients' experiences with this intervention. Such knowledge could potentially be helpful to improve healthcare practitioners' communication with patients, and thereby patients' overall care.

\section{Introduction}

As emphasised by the World Health Organization, cancer is a leading cause of morbidity and death. ${ }^{1}$ In Europe, it is estimated that there are 3.7 million new cases and 1.9 million deaths each year. These figures are expected to increase. ${ }^{2,3}$ The most common forms of cancer are female breast cancer, colorectal, prostate and lung cancer. Together they account for $50 \%$ of all diagnosed cases. ${ }^{4}$ The economic burden of caring for patients with cancer reached 126 billion euros in 2009. ${ }^{5}$
The use of complementary and alternative medicine (CAM) is high and increasing. ${ }^{6}$ Results of the latest published systematic review suggest an increase in point prevalence of CAM use in patients with cancer from $25 \%$ (95\% confidence interval [CI]: $12 \%$ to $38 \%$ ) before 1990 to $44 \%$ (95\% CI: $38 \%$ to $60 \%$ after $2000 .{ }^{7}$ The point prevalence was lower in Europe (34\%, $95 \%$ CI: $25 \%$ to $44 \%$ ) than in North America (46\%, $95 \%$ CI: $35 \%$ to $56 \%$ ), and it was lower in Scandinavia compared to German-speaking countries. General use of CAM in the Danish population was 26\% in $2010 .^{8}$ Four in 10 Danish received

May 15, 2018

accepted after revision

August 8, 2018

published online

September 21, 2018
DOI https://doi.org/

10.1055/s-0038-1670689.

ISSN $1475-4916$.
Copyright $\odot 2019$ The Faculty of Homeopathy
License terms

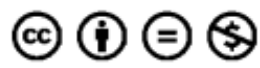


women with breast cancer diagnosis reported CAM use 12 to 16 weeks post-surgery; ${ }^{9}$ and $49 \%$ of patients who had recently completed conventional colorectal cancer treatment reported some form of CAM treatment in the past month. ${ }^{10}$ Although updated prevalence data for CAM use for all categories of patients with cancer in Denmark are lacking, these two surveys suggest CAM use among Danish patients with cancer may be comparable to patients in other countries. CAM is used by both men and women, and in different sub-groups of patients. ${ }^{11-16}$

Homeopathy is a CAM therapy that was developed by Hahnemann (1751-1843), a German physician who based his system of medicine on the law of similars-'let like be cured by like'. It involves consultations with a homeopath and the prescription of highly diluted homeopathic medicines which can be prescribed in a variety of ways. ${ }^{17}$ A recently published systematic worldwide review suggests about 4\% (range: $0.7-9.8 \%$ ) use homeopathy, ${ }^{18}$ and it is more commonly used in Europe than in North America. ${ }^{6}$ It is used by patients with a variety of clinical problems, including recurrent respiratory tract infections, migraine headaches, back pain, fatigue, allergic and skin conditions, sleep disturbances, and mental health problems. ${ }^{19,20}$

Homeopathy is the second or third most used CAM therapy by patients with cancer in Europe. ${ }^{21,22}$ A German cohort study found that patients with cancer using homeopathy are more likely to be younger, have higher education and higher income, compared to patients solely using conventional treatment. ${ }^{23}$ Although no epidemiological studies report on use of homeopathy among patients with cancer in Denmark, similar characteristics have been found in Danish breast and colorectal cancer CAM users. ${ }^{9,10}$ Results of the German study suggested that the homeopathy group had a longer disease history than patients with cancer receiving conventional treatment, indicating that the two groups entered the study at different disease phases. Their quality of life, levels of anxiety, depression and fatigue scores were, however, comparable. ${ }^{23}$ Danish patients with breast cancer using CAM were found to be less likely to suffer from co-morbid diseases, compared to those not using CAM therapies. ${ }^{9}$

Whilst it is known that homeopathy is used by a significant proportion of patients with cancer, ${ }^{23-28}$ a search of databases including AMED, CINAHL, Cochrane Library, ProQuest and SCOPUS, failed to identify any qualitative studies exploring experiences among patients with cancer with treatment provided by homeopaths, and it is one of the areas highlighted for future research. ${ }^{24,29,30}$ Hence, there is a gap in knowledge of cancer patients' experiences with homeopathic treatment. Moreover, no studies have reported on the use of homeopathy among these patients in Denmark. Therefore, this study aimed to gain a first insight into reasons for and experience with treatment provided by homeopaths among Danish patients with cancer.

\section{Methods}

The study included a purposive sample of Danish patients with cancer who had used homeopathy alongside conven- tional cancer treatment. Semi-structured interviews were carried out and analysed using thematic analysis. ${ }^{31}$ We did not aim for saturation of data, but to provide an initial insight into experiences with homeopathic treatment among cancer patients in Denmark. The study was carried out as part of a Master of Science (MSc) course at the University of Central Lancashire (United Kingdom). Ethics approval was obtained from the University's Ethics Committee.

\section{Inclusion Criteria}

Inclusion criteria for patients: Medical diagnosis of cancer, current conventional cancer treatment with homeopathy as an adjunct therapy, having had a minimum of four consultations with a homeopath and currently being under the care of a homeopath. Participants had to be at least 18 years of age and able to speak and read Danish.

We did not limit inclusion criteria to patients with any particular type of cancer diagnosis to obtain knowledge from a greater variety of patients with cancer. Including patients who used homeopathy in parallel to conventional treatment provided us with an opportunity to compare and contrast patients' experiences with the different treatments.

Inclusion criteria for practitioners: Working as a 'classical' homeopath, to have a minimum of 5 years of clinical experience with patients diagnosed with cancer and/or had to be working at a hospital under peer supervision and seeing at least 10 patients with cancer per week.

\section{Recruitment}

The goal was to interview 12 patients. As part of our recruitment strategy, we asked homeopaths and a Danish association for patients with cancer who are interested in or who use CAM therapies (Kræftforeningen Tidslerne) to inform about the study. Letters were sent by e-mail to homeopaths identified through the Danish Society of Homeopaths, the only professional organisation for homeopaths in Denmark (which has 40 members), asking them to pass on information sheets to their cancer patients. After several requests to the homeopaths, three cancer patients contacted the researcher. In addition, we encouraged patients who participated to inform other patients who might fulfil the inclusion criteria to participate. Three patients were recruited through the association and three through other patients. One patient died prior to study start: hence, five were interviewed.

\section{Intervention}

Interviewees consulted homeopaths offering individualised treatment and practising 'classical homeopathy'. The fact that treatment was individualised means that it was tailored to the individual patient. The term 'classical homeopathy' is used to describe the prescription of single homeopathic remedies on the basis of the individual patient's symptom picture. This means that different homeopathic remedies could be prescribed for different patients suffering from the same diagnosis, following a homeopathic interview. ${ }^{17}$ The treatment was provided by three homeopaths, two Danish and one German. The two Danish homeopaths were recruited through the Danish Society of Homeopaths and both had 5 years' 
experience in treating patients with cancer. The German homeopath was recruited through patients. This homeopath was seeing at least 10 cancer patients per week in Germany, but was also treating some patients in Denmark. One practitioner was a medical doctor, the second a psychologist and the third was a homeopath as the primary profession.

\section{Data Collection}

Potential participants were sent information about the research with the interview questions (required by the Ethics Committee). Questions were kept open to obtain patients' own experiences and views, and to avoid leading them in a particular direction. The interview-guide questions included patients' reasons for choosing homeopathic treatment, what they wanted treatment for, their experience of using homeopathy and conventional treatment in combination, their overall experience, and any recommendations they would make for others who might consider consulting a homeopath. Before this study took place and as a part of the MSc Homeopathy course at the University of Central Lancashire, United Kingdom, the researcher carried out a literature search in the area of homeopathic cancer treatment. The literature search gave the researcher a broad knowledge in the area. Together with the insight gained from contact with several people with cancer known to the Kræftforeningen Tidslerne, the interview questions were developed.

Interviews were conducted by one researcher (CY), who has a background as a homeopath and qualitative researcher. The interviewer had not treated any of the included patients, but her background as a homeopath could potentially influence interviews. However, through her education and clinical practice, she had extensive training and clinical experience. This includes training at the polyclinic at the University of Westminster as part of a Bachelor of Science Degree in Homeopathy, as well as training in interviewing as part of a qualitative research project. Her background enabled her to ask open-ended and non-leading questions, and to establish a good researcher-participant relationship. We believe this contributed to encouraging patients to speak freely and share their thoughts and experiences. Moreover, she used the interview guide as a basis for all interviews.

The interviewees were asked where they wanted to be interviewed; either in their home, in an office or over Skype. Four interviewees chose a live interview in their home and one choose a Skype interview. Semi-structured interviews of up to 1 hour were scheduled, and interviewees were encouraged to stop interviews at any time or to have a break if needed. Open-ended questions were used, together with active listening and letting interviewees speak as freely as possible during interviews. The intention was to ensure good rapport and a rich understanding of interviewees' thoughts and experiences, with as little influence of the researcher's pre-determined understanding as possible.

All interviews were audio-recorded and transcribed by the first researcher ( $\mathrm{CY}$ ). Transcripts were compared to audio recordings by another person who is a professional translator and who also checked the accuracy of translations from
Danish to English. Moreover, all transcripts were sent back to interviewees for correction or confirmation. Also, short overviews of the interviews were sent back to the interviewees for confirmation of the meaning. Four out of five participants responded to the transcripts, whereas the fifth was unable to do so for health reasons. Three out of the four participants who responded agreed to the transcripts and summaries as they stood, whereas the fourth had one minor correction to the transcript, but this did not affect data analysis.

\section{Data Analysis}

Thematic analysis was used to analyse participants' responses. The researchers have a background as homeopaths, which may have influenced analyses. ${ }^{32}$ An advantage of having such a background was that the researchers have experience in treating patients with cancer and could therefore better understand the interviewees' situation. To limit the influence of any pre-determined perceptions of the intervention, the researchers carefully considered and based their analyses on interviewees' responses. Particular caution was paid to development of any themes that would be in line with the core principles of homeopathy, which include the so-called principle of similars and development of patients' state of health according to a hierarchical model often referred to as 'Hering's observations'.

The interviews were analysed through a process of assessing and revisiting the data transcripts on numerous (more than 50) occasions and the results are presented in this article. Interview transcripts were coded, mainly using codes with patients' own words. Codes were checked and revised as necessary each time the data were revisited. Codes were then grouped together in accordance with what the researchers considered to be themes. Each theme was described and patients' quotes were used to illustrate each theme. Trustworthiness was based on the extent to which themes shed light on the research question. ${ }^{31,33}$

\section{Ethics}

All procedures performed in the study were in accordance with the ethical standards of the institutional research committee and with the 1964 Helsinki declaration and its later amendments or comparable ethical standards. Informed and written consent was obtained from all individual participants included in the study. For confidentiality reasons, participants were informed that their real names would not be used in the published results. The name attached to each presented patient quote is therefore fictitious.

\section{Results}

\section{Participants}

The goal was to interview 12 persons, but only 6 patients agreed to participate in the interview study, and one died prior to start. This was the total number of patients approached who agreed to participate in the study. The reason for the low response is not known, but we assume it is partly because 
Table 1 Participants' characteristics

\begin{tabular}{|l|l|l|l|l|l|}
\hline Name & $\begin{array}{l}\text { Age } \\
\text { (years) }\end{array}$ & $\begin{array}{l}\text { Type(s) of } \\
\text { cancer }\end{array}$ & $\begin{array}{l}\text { Time since } \\
\text { diagnosis (years) }\end{array}$ & $\begin{array}{l}\text { Used homeopathy } \\
\text { prior to diagnosis }\end{array}$ & $\begin{array}{l}\text { Length of interview } \\
\text { (minutes) }\end{array}$ \\
\hline Sally & 55 & Lung, previously breast & 3.5 & No & 56 \\
\hline Karen & 53 & Ovary and breast & 3.0 & Yes & 84 \\
\hline Simon & 85 & Prostate, skin & 13.0 & No & 23 \\
\hline Ida & 63 & Breast & 10.0 & No & 36 \\
\hline Claire & 68 & Breast & 3.5 & Yes & 42 \\
\hline
\end{tabular}

${ }^{\text {a } F o r ~ c o n f i d e n t i a l i t y ~ r e a s o n s, ~ p a r t i c i p a n t s ' ~ r e a l ~ n a m e s ~ a r e ~ n o t ~ u s e d . ~}$

classical homeopathy is rather unknown in Denmark, so the number of cancer patients who seek a homeopath is small.

Although we had hoped for a greater age variety in participants, those included were middle aged or older (range: 53-85 years). They had experiences with five different types of cancer, which had been first diagnosed between 3 and 13 years prior to the study. Some had past experiences with homeopathy, whereas others did not. Further details may be found in -Table $\mathbf{1}$.

\section{Interviews and Developed Themes}

Interviews lasted from 22 to 84 minutes (median 42 minutes). The relative brevity of interviews was to reduce the amount of any distress for participants, most of whom struggled with low levels of energy. Five themes representing the patients' experiences were developed:

1. Concerns and hopes

2. Obstacles and support

3. Internal health locus of control

4. Whole person approach

5. Improved well-being.

\section{Concerns and Hopes}

A common theme was that participants sought out treatment by a homeopath as there was an absence of hope provided by their conventional practitioners, or they had lost hope in conventional treatment because of a relapse and placed their hope with homeopathy.

'I became aware of homeopathy when I had a relapse of breast cancer in January 2008. For a rather long time, I had had some cough and my general practitioner sent me to the hospital and they carried out some scans, which showed that I had water in the lungs and they said that possibly I had metastases and it was incurable. They couldn't say what my future prospects were, but since it was an aggressive type of cancer they didn't think I had much time left'. (Sally)

As illustrated by this example, some concerns were directly associated with the disease and the prognosis. Others were concerned about side effects of conventional cancer treatment, which could result in long-term adverse effects. Claire had learned this through her own family: 'I chose to do without the radiation treatment because I think it has an adverse effect on the body. My sister had both breasts removed [...] and she had radiation treatment and she still has strong symptoms from it today'.
Interviewees suggested that other patients with cancer should consider giving it a chance, as illustrated by Sally who said: 'I will definitely recommend trying it and examining what's on the market and making an introductory conversation and seeing if it could work and then try'. Interviewees' recommendations to consult with a homeopath were based on their own experiences, what they had learned from other patients and as a result of what they had been told by their homeopath, as illustrated by Simon who said: 'Began at the homeopath, who had told my wife that he had seen some good results with cancer and I started [...] in 1998/1999'.

Patients also had some concerns about homeopathic treatment. Karen expressed some doubts associated with practitioners' competence: 'It occurs to me that if you search for a homeopath, how do you know it's not a quack?' Another participant expressed concerns with using both treatments simultaneously, as the meaning of new symptoms could be difficult to interpret. 'And then I could feel that both the lump and the scar tissue had become a bit bigger, but it's difficult to know if it's the cancer lump which has grown or if it's just the gland that swelled up because some kind of cleansing takes place. You never know'. (Claire)

So, there was some uncertainty about the treatments and an acknowledgement of the importance of conventional cancer treatment, when at the same time being aware of its limitations and potential risks of adverse effects. None of the participants suggested replacing conventional treatment with homeopathy, but to use it as a supplement. Nevertheless, all interviewees saw hope and opportunities in homeopathic treatment, as illustrated by the following statements: 'Actually I want to advise everybody else to supplement immediately no matter if you choose to be operated on or the radiation treatment or the chemo treatment'. (Claire) And: 'Find a homeopath, that is my best advice'. (Karen)

\section{Obstacles and Support}

Support was a major issue for the interviewees and they explained how friends and family had helped them to find a homeopath and supported their choice of treatment, as illustrated by Sally: 'Then my friends and I started to examine other alternative possibilities [from conventional treatment]'.

However, interviewees expressed that at times they felt their autonomy was threatened by healthcare practitioners as well as their own families. It was difficult for them to be resolute in their own choice of healthcare. They felt that 
some healthcare practitioners and family members ascribed them a passive role, leaving no space for them to be active and take responsibility for their own health. This felt like an obstacle to feeling well and it compromised their hope for healing. One participant expressed this by stating: ' $[. .$. because homeopathy isn't very well known in Denmark, your friends and family try to talk you out of it too'. (Karen)

Karen also mentioned how oncologists made her frightened and angry when they attempted to talk her out of using other complementary therapies: 'Once I saw an oncologist when I got Iscador [a type of CAM therapy that is part of anthroposophic medicine]. I said I wanted to take it during chemo treatment and she said she knew what it was; everybody who had taken it were all dead. And that is just such a horrible thing to say, right?'

The interviewees felt supported by their homeopaths as it helped them to talk with someone who they felt was empathic, someone who understood them and who took them seriously. Some participants considered the homeopath to be ' $[. .$.$] a nice person and nice to talk with' (Simon),$ whereas for others the homeopath played a much bigger role and was a significant source of support. One participant expressed this as: 'So yes, but then it's just that you become dependent on the homeopath almost, not [fully] dependent on, but yes, it's a lifeline you get, it really is. Yes, if I'd only known it earlier, because [the homeopath] was there for me at once. He writes warm greetings and I thought all right, I've really got one here who supports me. I could feel that there was one who would take care of me and help me become fit again. It has been good with homeopathy from the beginning'. (Karen)

\section{Internal Health Locus of Control}

The interviewees described what can be understood as health locus of control, a concept which is based on Rotter's theory of locus of control. ${ }^{34}$ Patients with a strong internal health locus of control (IHLOC) believe their own behaviour to have a strong influence on their health, in contrast to persons with an external health locus of control, where health is related to external factors that are difficult to influence. ${ }^{35}$

Patients did, to a considerable extent, take responsibility for their own health and they had a desire to make their own decisions about any existing treatment options. 'You [the oncologist] shouldn't worry about me at all: I take the responsibility, you don't have to. [...] so, for me, it has been the start of a long course with all sorts of problems, but also the start of me taking the matter into my own hands each time there was something, right'. (Ida)

They felt they had the right to make informed decisions about their own treatment, and they disliked when they were told to go home and just do as they were told. 'And it was also like some of the doctors gave me the impression to go home to your kitchen. We take care of this, it's our business: [...] they meant it in a nice way, but there are many of us who just can't think this way. And I have to know what's going on so I asked: What's it called the chemo treatment, what does it consist of or e.g. how is a biopsy carried out? [...] I asked and I asked and then I went home and searched with my computer and then I had even more questions and I posed every single question every time and they were so tired of me. And I don't feel this is fair'. (Karen)

Other patients described oncology practitioners who supported their freedom of choice in healthcare, thereby supporting patients' IHLOC. 'I think that gradually in the hospital service you meet with the opportunity to choose what you can use. Of course they tell you what solution they find as the best, and that's fair enough, but there are some doctors who are sensible and say that it's okay you take what you can use and it's your choice. [...] And one of them said that if you feel like it stresses you, if we suggest chemo therapy, then we should stop suggesting it. And I said that I should under no circumstances have the chemo and then she wrote in my papers: No chemo'. (Claire)

Patients' strong IHLOC was associated with not automatically accepting what they heard. The interviewees questioned what they were told both by the conventional healthcare practitioners and by the homeopaths. Sally did not agree with her homeopath and chose another solution than suggested. 'I was [...] asked if I would consider [...] taking a break from the chemo. They thought my final course would be better, because their experience was that especially breast cancer women got painful final courses, and they thought that this would be much better with the homoeopathy, so they could help me have a better death. Then I went home and thought about it [...] but it was too early. I was simply not ready [...] and I chose to continue the chemotherapy [...]'

Participants searched for information, for example, over the Internet and tried to understand how certain treatment modalities worked and what results they could expect. They wanted to make informed choices. They did not choose to use either CAM or conventional treatment, but they combined different treatment modalities in a way that seemed 'logical' or 'right' to them. They showed compliance both to conventional treatment offers and check-ups, as well as dietary advice offered by the homeopaths when they felt this made sense. However, after weighing the pros and cons, they could decide to abstain from a diagnostic or therapeutic approach if they believed it was associated with considerable disadvantages. Such decisions were not easy to reach, but patients still made what they felt was their choice. Claire expressed this as: 'When I chose to do without that chemo treatment I knew I had to try something else [...]. Now I have this check-up on Friday and I have chosen to do without the mammography because the lump I have is placed almost right under the armpit and then I don't see any reason that the breast should be manhandled. When I had the last mammography [the nurse] said they had to stop it because the pictures couldn't get better where the lump was and then I thought ok then it's not useful [...] I really want to have these check-ups because it's nice after all to follow the development. It's really difficult to judge if it's swollen glands or if it's scar tissue or if it's cancer [...]'.

\section{Whole Person Approach}

Participants' statements were related to a holistic way of thinking. As Karen expressed it: 'You come as a whole human being. You can't just come as a body'. The interviewees felt 
these views and values were shared by their homeopaths, and they felt appreciated as a whole person.

Sally said: 'Obviously the advantage of the homeopathic approach is that you are interested in the whole person, which is what you really miss in the conventional system. If you have metastases in the lungs then it's only the $30 \mathrm{~cm}$ under the head and down to the navel that is interesting [...] It's really like you're divided in small sections and you can't discuss the other things [...]. Not to mention the mental part-the fact that the mental and physical things hang together, that is very important too'. In addition, Sally felt that homeopathy had helped her with physical symptoms: 'Ten years ago, as I went to the chemo treatment for the first time, I was very, very ill. Each time I'd had a treatment, I was ill in bed from 3 days to 1 week and I threw up and felt really, really bad and had headache, and this time I haven't felt these symptoms, so I believe homeopathy has helped with this'.

In this quote, Sally explains what a reductionist way of thinking within the healthcare system means to her. She feels divided into small parts and not seen as a human being. She wants to be looked at as a whole person where both her mental and physical problems are seen as connected and taken care of. Conventional cancer care clinicians were described as focussing on the local cancer symptoms, rather than on the whole person.

\section{Improved Well-Being}

Participants reported how homeopathy had helped them cope with symptoms of depression, poor memory and concentration, as well as physical symptoms such as a tennis elbow, acute winter illnesses and backache. They found that homeopathy improved their overall well-being both physically and mentally, and the low energy often seen in patients with cancer. Claire noted how she felt '[...] really well with the homeopathic therapy and mentally I can feel a change too. It simply gives more energy'. Sally recalled that 'I was afraid of relapsing into a severe depression once again, which I've had before and been hospitalised with, but I believe the homeopathic therapy helped me step down the [conventional medication]. After a few months I was done with it and I'm really happy about that. I haven't seen a trace of depression since then'.

Another patient described a multitude of side effects arising from conventional treatment. After homeopathic treatment, she described 'becoming human again': '[My] homeopath, then she said, yes but then there's these side effects from the radiation treatment: we'll handle them in this and that way and there was the side effects from the chemo, we'll handle them in this and that way [...]. And that helped for the side effects and that is amazing, right? [I] couldn't feel my body or skin, I couldn't see, watch television, read books or think. I couldn't drive a car, I couldn't feel my feet. I was on the brink at this time. My nails had started to turn blue and I was so ill. And then the common things: You can't taste or smell anything, and I couldn't feel my hands. I burned myself and cut myself, you see. I could barely eat by myself because sensation was gone because of the chemo treatment. That is what the uncomfortable thing is: I thought I would never become a human again. But thanks to homeopathy [I did so]'. (Karen)

\section{Summary of Themes}

This qualitative semi-structured interview study suggests that patients with cancer sought treatment by a homeopath in response to concerns about conventional medical treatment, relapses and the poor prognoses offered. Their choice of homeopathy as a supplement to conventional cancer care was associated with increased hopes of better health. Participants felt supported by their homeopaths and this was sometimes in contrast to a perceived lack of support from oncologists, families and friends.

Participants felt their right to self-determination had been compromised and they appreciated the approach taken by their homeopaths. In particular, the holistic worldview held by their homeopath was welcomed, with participants describing how enhanced mental and physical well-being was the main outcome of the treatment. However, this did not mean that the interviewees had uncritically accepted the treatment that was offered by homeopaths. Their descriptions leading to the theme of the IHLOC suggest they sought information from various sources to make informed decisions for their own healthcare. The complementary homeopathy treatment was described as a whole-person approach contributing to improvements in patients' feeling of wellbeing.

\section{Discussion}

Five themes were developed in this first qualitative study providing an initial insight into reasons for the use of and experience with homeopathic treatment among patients with cancer. Although no former qualitative study has reported on the experiences with homeopathy in this patient group, some have reported on experience with other CAM therapies. $^{36-38}$

As in the current homeopathy study, reasons that patients choose CAM treatments may include CAM practitioners' focus on improving well-being. ${ }^{36,37}$ There is some evidence to suggest that patients with cancer, and using homeopathy as an adjunct to usual cancer care, experience improved wellbeing and better quality of life, ${ }^{25,28}$ as was mentioned by all five interviewees in the current study. Following homeopathy treatment, others also found improvement in the wellknown fatigue symptom of patients with cancer. ${ }^{25}$

The use of other CAM therapies by patients with cancer has been found to be partly motivated by their concerns, in particular concerns about side effects associated with conventional treatment. ${ }^{38-40}$ As a result, there may be a risk that some patients choose to decline an offer of conventional treatment. The interviewees in this study used homeopathy as a complement (and not an alternative) to conventional cancer care, which is advisable and ethically appropriate to ensure patient safety. Some decided not to use all the interventions they were offered. These decisions followed if patients anticipated that the risks of side effects outweighed any potential benefits. Such decisions were not taken lightly, but only after careful consideration of the information provided by healthcare practitioners, and on the basis of patients' own experiences and anecdotal reports from other patients. Patients with cancer 
who were using CAM in some studies had a strong need to be involved in and control decisions that would affect their healthcare. ${ }^{39}$ Deciding not to take up an offer of some form of cancer treatment may be associated with concerns about side effects from conventional cancer treatment. ${ }^{40}$ The need to stay in control of healthcare decisions was in our study described through the theme of a strong IHLOC. Strong IHLOC has been associated with high CAM use and high CAM appraisal. ${ }^{41}$ We suspect that high IHLOC became a theme in our study as these patients are more likely to seek other treatment options, as opposed to patients with low IHLOC who we would expect to be more likely to rely solely on the advice given by oncologists and therefore use conventional treatment only.

Are patients with a high IHLOC also more likely to seek homeopathy treatment because they feel no hope for cure is offered by their healthcare practitioners, and they refuse to accept a poor prognosis? The interviewees in this study described consulting with homeopaths, as little or no hope was given by their conventional practitioners, or they had lost hope in conventional treatment because of a relapse. Some patients experienced difficulties in the communication with oncologists about CAM treatment. Karen mentions how 'they tried to talk her out of it'. Rossi proposes the idea that reluctance of giving false hope of cure among patients with cancer may impact oncologists' (lack of) integration of CAM in oncology departments. ${ }^{42}$ We suggest oncology practitioners should take patients' concerns and wishes seriously and facilitate constructive patient-clinician communication. A form of communication where patients' views and wishes are rejected could be a potential risk factor from an oncology practitioner's viewpoint, as it may lead to patients choosing to reject or discontinue conventional cancer care. ${ }^{43} \mathrm{~A}$ more open and positive form of communication, where clinicians listen to patients' concerns and wishes, is more likely to result in patients using CAM therapies as a complement, rather than an alternative. Such communication is likely to facilitate a better therapeutic relationship, it provides a better basis for shared decision-making in healthcare, and it is more in line with a patient- or person-centred approach to the relationship and the treatment.

\section{Strengths and Weaknesses of This Study}

This qualitative study was the first to examine reasons for use of and experience with homeopathic treatment among patients with cancer. It was also the first ever study assessing experiences with homeopathy among Danish patients with cancer. The small number of interviewees was diagnosed with a diverse range of cancer types (lung, female breast, prostate, skin and ovarian cancer). The strengths of the qualitative approach are the exploration of subjective viewpoints and the in-depth information among patients with cancer.

The small sample size is a weakness of this study. This was in part due to the fact that the study took place in Denmark, where 'individualised' or 'classical' homeopathy is relatively unknown. This may have influenced the experiences of the interviewees when discussing homeopathic treatment with their oncologists and it may also have had an impact on which patients sought homeopathic treatment. It is possible that their experience of using homeopathic treatment as an adjunct to usual cancer care may vary among different groups of cancer patients (tumour location and stage of cancer), and experiences may be different for patients in other countries. We did not seek to address issues surrounding the generalisability or transferability of the study, which could be aimed for in a future meta-synthesis including qualitative studies which also use approaches such as systematic sampling and triangulation. ${ }^{44}$

Only a single male patient participated, thereby providing little insight into 'the male perspective' in this particular field (-Table 1). Patients' age ranged from 55 to 85 years. The results might have been different had younger patients been interviewed. To reduce any strain put on patients, interviews were kept as short as possible, which may also have contributed to somewhat limited description of the developed themes.

A number of approaches were used to contribute to the trustworthiness of the research. This included the use of a 'bottom up' approach, basing the development of codes and themes on the data, rather than a 'top down' approach which would start out with a pre-defined framework of understanding. Some of the questions were pre-determined in order to learn from experiences with, and views of, the intervention among patients with cancer. Questions were, however, openended (as opposed to closed 'yes/no' questions) to capture better the patients' own understandings. The developed themes provide an initial and limited insight into experiences with homeopathic treatment among patients with cancer.

\section{Recommendations}

Future research should be conducted to consider the themes identified through this small qualitative study, to expand on the description of themes, as well as to examine additional issues considered to be of importance to cancer patients consulting with homeopaths. This should include exploration of positive as well as negative experiences that patients may have with this intervention. Researchers could also consider limiting inclusion criteria to certain groups of patients with cancer, as some may have different prognoses and may choose different treatment pathways. Communication and collaboration between CAM and conventional practitioners should be explored. This may contribute to ensuring the safety of patients.

\section{Conclusion}

Five themes developed through this study provide initial insight into reasons for, and experiences with, the use of treatment provided by homeopaths as an adjunct to usual cancer care. The cancer patients in this study sought homeopathy to address their hopes and concerns and to help them face obstacles and find support. They were actively taking responsibility for their own health and valued the whole person approach used by their homeopaths. The participants reported improved well-being at the physical and mental levels. Further research is needed to learn more from experiences with this 
intervention among patients with cancer and about the communication between clinicians and patients about such treatment.

\section{Highlights}

- This is the first qualitative study exploring cancer patients' experiences with homeopathy.

- Patients described concerns, hopes, obstacles and support in their treatment.

- Homeopathy was considered to be a whole person approach.

- Patients felt in control of their treatment and their wellbeing improved.

- This was a small study and more research is needed in this clinical field.

\section{Funding}

This work was partly supported by Fonden af 1870 . The fund had no role in the study design, or in the collection, analysis and interpretation of data; nor in the writing of the report, and in the decision to submit the article for publication.

\section{Conflict of Interest \\ None declared.}

\section{Acknowledgement}

We are most grateful to the study participants and to Charlotte Lillegaard Petersen for transcript checking.

\section{References}

1 World Health Organization. Cancer: Data and Statistics Available at: http://www.euro.who.int/en/health-topics/noncommunicablediseases/cancer. Accessed April 11, 2018

2 Møller B, Fekjaer H, Hakulinen T, et al. Prediction of cancer incidence in the Nordic countries up to the year 2020. Eur J Cancer Prev 2002;11(Suppl 1):S1-S96

3 Gatta G, Mallone S, van der Zwan JM, Trama A, Siesling S, Capocaccia R; EUROCARE Working Group. Cancer prevalence estimates in Europe at the beginning of 2000. Ann Oncol 2013;24:1660-1666

4 Ferlay J, Steliarova-Foucher E, Lortet-Tieulent J, et al. Cancer incidence and mortality patterns in Europe: estimates for 40 countries in 2012. Eur J Cancer 2013;49:1374-1403

5 Luengo-Fernandez R, Leal J, Gray A, Sullivan R. Economic burden of cancer across the European Union: a population-based cost analysis. Lancet Oncol 2013;14:1165-1174

6 Frass M, Strassl RP, Friehs H, Müllner M, Kundi M, Kaye AD. Use and acceptance of complementary and alternative medicine among the general population and medical personnel: a systematic review. Ochsner J 2012;12:45-56

7 Horneber M, Bueschel G, Dennert G, Less D, Ritter E, Zwahlen M. How many cancer patients use complementary and alternative medicine: a systematic review and metaanalysis. Integr Cancer Ther 2012;11:187-203

8 Christensen AI, Ekholm O, Davidsen M, Juel K. Sundhed og sygelighed i Danmark 2010 - og udviklingen siden 1987. Statens Institut for Folkesundhed, Syddansk Universitet; 2012

9 Pedersen CG, Christensen S, Jensen AB, Zachariae R. Prevalence, socio-demographic and clinical predictors of post-diagnostic utilisation of different types of complementary and alternative medicine (CAM) in a nationwide cohort of Danish women treated for primary breast cancer. Eur J Cancer 2009;45:3172-3181
10 Nissen N, Lunde A, Pedersen CG, Johannessen H. The use of complementary and alternative medicine after the completion of hospital treatment for colorectal cancer: findings from a questionnaire study in Denmark. BMC Complement Altern Med 2014; $14: 388$

11 Bishop F, Rea A, Lewith H, et al. Complementary medicine use by men with prostate cancer: A systematic review of prevalence studies. Eur J Integr Med 2010;2:179-180

12 Klafke N, Eliott JA, Wittert GA, Olver IN. Prevalence and predictors of complementary and alternative medicine (CAM) use by men in Australian cancer outpatient services. Ann Oncol 2012;23:1571-1578

13 Kristoffersen AE, Norheim AJ, Fønnebø VM. Complementary and alternative medicine use among Norwegian cancer survivors: gender-specific prevalence and associations for use. Evid Based Complement Alternat Med 2013;2013:318781

14 Molassiotis A, Fernandez-Ortega P, Pud D, et al. Complementary and alternative medicine use in colorectal cancer patients in seven European countries. Complement Ther Med 2005; 13:251-257

15 Molassiotis A, Scott JA, Kearney N, et al. Complementary and alternative medicine use in breast cancer patients in Europe. Support Care Cancer 2006;14:260-267

16 Molassiotis A, Panteli V, Patiraki E, et al. Complementary and alternative medicine use in lung cancer patients in eight European countries. Complement Ther Clin Pract 2006;12:34-39

17 Fisher P. What is homeopathy? An introduction. Front Biosci (Elite Ed) 2012;4:1669-1682

18 Relton C, Cooper K, Viksveen P, Fibert P, Thomas K. Prevalence of homeopathy use by the general population worldwide: a systematic review. Homeopathy 2017;106:69-78

19 Becker-Witt C, Lüdtke R, Weisshuhn TE, Willich SN. Diagnoses and treatment in homeopathic medical practice. Forsch Komplementarmed Klass Naturheilkd 2004;11:98-103

20 Relton C, Chatfield K, Partington H, Foulkes L. Patients treated by homeopaths registered with the Society of Homeopaths: a pilot study. Homeopathy 2007;96:87-89

21 Lewith G. (2012) CAM use - the patients' perspective. In: CAMbrella. The Roadmap for European CAM Research. Bruxelles: Seventh Framework Programme; 2012

22 Molassiotis A, Fernadez-Ortega P, Pud D, et al. Use of complementary and alternative medicine in cancer patients: a European survey. Ann Oncol 2005;16:655-663

23 Guethlin C, Walach H, Naumann J, Bartsch HH, Rostock M. Characteristics of cancer patients using homeopathy compared with those in conventional care: a cross-sectional study. Ann Oncol 2010;21:1094-1099

24 Kassab S, Cummings M, Berkovitz S, van Haselen R, Fisher P. Homeopathic medicines for adverse effects of cancer treatments. Cochrane Database Syst Rev 2009;2:CD004845

25 Rostock M, Naumann J, Guethlin C, Guenther L, Bartsch HH, Walach $\mathrm{H}$. Classical homeopathy in the treatment of cancer patients-a prospective observational study of two independent cohorts. BMC Cancer 2011;11:19

26 Sencer SF, Zhou T, Freedman LS, et al. Traumeel S in preventing and treating mucositis in young patients undergoing SCT: a report of the Children's Oncology Group. Bone Marrow Transplant 2012; 47:1409-1414

27 Gaertner K, Müllner M, Friehs H, et al. Additive homeopathy in cancer patients: Retrospective survival data from a homeopathic outpatient unit at the Medical University of Vienna. Complement Ther Med 2014;22:320-332

28 Frass $\mathrm{M}$, Friehs $\mathrm{H}$, Thallinger $\mathrm{C}$, et al. Influence of adjunctive classical homeopathy on global health status and subjective wellbeing in cancer patients - A pragmatic randomized controlled trial. Complement Ther Med 2015;23:309-317

29 Milazzo S, Russell N, Ernst E. Efficacy of homeopathic therapy in cancer treatment. Eur J Cancer 2006;42:282-289 
32 Qualitative Study of Homeopathy as Adjunct to Usual Cancer Care Yde et al.

30 Frenkel M. Is there a role for homeopathy in cancer care? Questions and challenges. Curr Oncol Rep 2015;17:43

31 Braun V, Clarke V. Successful Qualitative Research. London, United Kingdom: SAGE Publications; 2013

32 Chenail RJ. Interviewing the investigator: strategies for addressing instrumentation and researcher bias concerns in qualitative research. Qual Rep 2011;16:255-262

33 Noble $\mathrm{H}$, Smith J. Issues of validity and reliability in qualitative research. Evid Based Nurs 2015;18:34-35

34 Rotter JB. Social Learning and Clinical Psychology. Englewood Cliffs, NJ: Prentice-Hall; 1954

35 Wallston BS, Wallston KA, Kaplan GD, Maides SA. Development and validation of the health locus of control (HLC) scale. J Consult Clin Psychol 1976;44:580-585

36 Hök J, Falkenberg T, Tishelman C. Lay perspectives on the use of biologically based therapies in the context of cancer: a qualitative study from Sweden. J Clin Pharm Ther 2011;36:367-375

37 Mulkins AL, Verhoef MJ. Supporting the transformative process: experiences of cancer patients receiving integrative care. Integr Cancer Ther 2004;3:230-237

38 Verhoef MJ, Rose MS, White M, Balneaves LG. Declining conventional cancer treatment and using complementary and alterna- tive medicine: a problem or a challenge? Curr Oncol 2008;15(02, Suppl 2):s101-s106

39 Verhoef MJ, White MA. Factors in making the decision to forgo conventional cancer treatment. Cancer Pract 2002;10: 201-207

40 van Kleffens T, van Leeuwen E. Physicians' evaluations of patients' decisions to refuse oncological treatment. J Med Ethics 2005; 31:131-136

41 Schützler L, Witt CM. Internal health locus of control in users of complementary and alternative medicine: a cross-sectional survey. BMC Complement Altern Med 2014;14:320

42 Rossi E, Vita A, Baccetti S, Di Stefano M, Voller F, Zanobini A. Complementary and alternative medicine for cancer patients: results of the EPAAC survey on integrative oncology centres in Europe. Support Care Cancer 2015;23:1795-1806

43 Salamonsen A. Doctor-patient communication and cancer patients' choice of alternative therapies as supplement or alternative to conventional care. Scand J Caring Sci 2013; 27:70-76

44 Finfgeld-Connett D. Generalizability and transferability of meta-synthesis research findings. J Adv Nurs 2010;66: 246-254 